\title{
ENDOGENOUS STRUCTURAL CHANGE AND CRISIS \\ IN A MULTIPLE TIME-SCALES GROWTH MODEL
}

A stylized formalization of the exhaustion and crisis of the fordist growth regime*

Frédéric LORDON**

(CNRS-CEPREMAP)

$n^{\circ} 9324$

November 1993

\footnotetext{
* I wish to thank Robert BOYER, Bruno AMABLE, Pascal PETIT, Dominique LEVY, Dominique GUELLEC and Denis PHAN for helpful comments and valuable discussions. Obviously all mistakes and shortcomings remain mine.

** Mailing address: Frédéric LORDON, CEPREMAP, 142 rue du Chevaleret, 75013 PARIS, FRANCE.
} 


\section{ABSTRACT \\ ENDOGENOUS STRUCTURAL CHANGE AND CRISIS \\ IN A MULTIPLE TIME-SCALES GROWTH MODEL \\ A stylized formalization of the exhaustion and crisis of the fordist growth regime}

Apart from selection and innovation processes, evolution can also be understood as the historical variability of macro-regularities and "growth regimes". The slow and endogenous twist of economic macro-structure thus makes up another aspect of the concept of evolution, particularly relevant in the interpretation of structural crisis such as the fordism crisis. In this line, a goodwinian growth model with dynamical scale economies and profit sharing is considered which tries to picture a simple scenario of the seventies crisis. It is shown that the downward shift of the Kaldor-Verdoorn's "productivity law", associated with the exhaustion of the fordist "productivity regime", can entail, in a nonlinear framework, a sudden breakdown from a high to a low growth and productivity path, in accordance with some of the stylized facts of the early seventies. Moreover, formal tools relying on "slow/fast" dynamical systems are presented which makes it possible to represent theses macro structural change and crisis as endogenous outcomes of the long run working of the fordist growth regime itself.

\section{RESUME}

\section{CHANGEMENT STRUCTUREL ET CRISE ENDOGENES DANS UN MODELE DE CROISSANCE A ECHELLES DE TEMPS MULTIPLES Une formalisation stylisée de l'épuisement et de la crise du régime de croissance fordiste}

A part les processus de sélection et d'innovation, l'évolution peut aussi être comprise comme la variabilité historique des régularités macroéconomiques constitutives de régimes de croissance. La déformation lente et endogène de la structure macroéconomique constitue donc un autre aspect du concept d'évolution, susceptible d'être au cœur de l'étude des crises structurelles telles que celle du fordisme. Dans cette perspective, on considère un modèle de croissance goodwinien en présence d'économies dynamiques d'échelle et de partage des profits, à l'aide duquel on tente de représenter un scénario très simplifié de la crise des années soixante-dix. On montre que le basculement de la loi de Kaldor-Verdoorn, représentatif de l'épuisement du régime de productivité fordien, peut entraîner dans un cadre non linéaire, la rupture brutale du sentier de croissance et de productivité d'un équilibre haut à un équilibre bas, conformément à certains faits stylisés du début des années soixante-dix. De plus le recours aux systèmes dynamiques dits "lents/rapides" permet de représenter ce changement structurel et cette crise comme produits endogènes du seul fonctionnement en longue période du régime de croissance fordien lui-même.

JEL Classification System : $041,030, C 62$

Mots-clés : Changement structurel, crise, croissance, bifurcations, systèmes dynamiques lents/rapides. systems

Key Words : Structural change, crisis, growth, bifurcations, slowlfast dynamical 


\section{INTRODUCTION}

The brutal slowing-down of the production and productivity growth, as well as the rise of unemployment, in the early seventies (see for a quantitative appraisal GLYN, HUGHES, LIPIETZ, SINGH, 1990) remain one of the major riddles economic theory is asked by recent history. Ignored for a long time, these "breakdown" stylized facts are now more and more acknowledged and taken into consideration by "new" econometrics (PERRON, 1990). ${ }^{1}$ However their theoretical enligthening is far from being completed, and surprisingly, few are the research programs which feel concerned with it.

Such violent accidents of the capitalist economies have at least the advantage to recall the relevance of a theoretical standpoint revolving around the ideas of instability and structural change inherited from SCHUMPETER and especially MARX. In this line, several approaches (BOWLES, GORDON, WEISSKOPF, 1983 ; FREEMAN and PEREZ, 1988 ; BOYER, 1988-a, -c) have chosen to interpret these breakdown stylized facts as manifestations of a structural crisis. Occuring after a long period of high and steady growth, they seem to witness to a failure in the dynamical reproduction of the economy. In this perspective, far from coming from accidental and external perturbations, the seventies irregularities refer to major internal structural changes. This historical episod then suggests a twofold theoretical approach.

1) The seventies crisis surely underscores the evolutionary character of the capitalist economies, but in a specific way which is quite different from the "usual" darwinoschumpeterian sense generally given to the word "evolution" (NELSON and WINTER, 1974 ; BOULDING, 1981). This paper then aims at pointing out the possibility and the specificity of such "another" evolutionary point of view which, unlike the interspecies competition, stems from a very macroscopic perspective. The concept of evolution it implies deals with changes taking place directly at a structural level, namely affecting

\footnotetext{
1 Even if the fact that these irregularities resort to "non-stationary unit-root" or to "breakdown"
} econometrics is still disputable. 
macroeconomic regularities and behaviours. To say it crudely, there is structural change when the economy "changes its laws". But this particular evolutionary standpoint also emphasizes the fact that the twist of the structure is an effect of its own working. In this perspective, the crisis appears as the outcome of an endogenous structural change process.

2) This particular evolutionary framework can be filled with economic contents borrowed to the french "Régulation school". Actually it is possible to extract from its emprirical and theoretical works (AGLIETTA, 1982, BOYER, 1988-a, -c) a crude scenario of the endogenous exhaustion of the "growth regime" which was at the core of the "roaring sixties" (BOYER, 1988-b). Basically, a so-called fordist growth regime initially built upon the extraction (and the distribution) of high productivity gains due to long and undifferenciated series, destroys its own basis as it progressively rises the standard of living and induces a replacement demand no longer homogenous but volatile and differenciated. This slow structural evolution then hurts the productivity "logic" of an industrial system previously dedicated to homogenous mass production and can be seen, at least partially, at the root of the productivity slowdown and then of the whole fordist regime crisis.

Even if rough and partial, this stylized scenario both is very representative of the "structural" evolution we think to, and underlines the particular difficulties "Regulation" macroeconomic models of the crisis are faced with :

- Firstly, the breakdown crisis to which the endogenous structural change progressively leads, rises a specific problem. In particular, it calls for formal tools capable to capture this kind of brutal dynamical irregularity and therefore picture the fact that the structural drift has an effect on the shape of the growth path.

- But the main concern of the paper is with the idea of an endogenous twist of a macroeconomic structure. This implies both to distinguish and articulate two different timescales dynamics. Actually there is a double link between the short dynamics of the growth (or accumulation) cycle and the long "structural change" dynamics : i) as recalled at once, the growth cycle is shaped by the structural framework within which it takes place; but ii) reciprocally, the repetition of the growth cycle induces, in the long run, slow and 
endogenous transformations of the structure itself. Therefore, if the structural framework can be considered as quasi invariant within the time-scale of the accumulation cycle, this hypothesis is no longer valid in the long run. How can be modelled both the distinction and the interaction between different time-scale dynamical processes is the corner stone of the present "structural" evolutionary standpoint, and the central question of this paper.

The paper is then organized as follows. The first section is devoted to setup the general theoretical framework within which the present modelling exercise is to take place. First of all it is useful to state a bit more precisely the particular evolutionary standpoint referred to above. Then is briefly and partially outlined (one of) the Regulation interpretation(s) of the crisis with a special focus on the notion of "productivity regime".

The second section presents the general features of a goodwinian growth model (à la GOODWIN-1967). Choosen because of its tractability, it also and above all acknowledges the proximity between GOODWIN's general project and the purpose of the present paper : embodying SCHUMPETER and (especially) MARX's intuitions in formal frameworks. This section emphasizes the main extension given to GOODWIN's model, namely the introduction of a technical change law à la KALDOR-VERDOORN. This extension has both economic and formal consequences. First it makes growth endogenous, whereas it was driven by an exogenous productivity trend in Goodwin's model. The introduction of a dynamical scale economies mechanism also provides an original way to make technical change endogenous, contrasting with the extensions previously proposed in this line which relied on a kaldorian technical change function (KALDOR, 1961) (see for instance VAN DER PLOEG, 1984, 1987) or on learning-by-doing processes à la ARROW (1962) (see DE NICOLO, 1988). Moreover this technical change law will appear as an important structural element, in fact a synthetic macroeconomic expression of the "productivity regime", and will be directly concerned by the structural change process. At last, formally speaking, the KALDOR-VERDOORN's law, when specified under a nonlinear form, may lead to multiple equilibria, the existence and the stability of which are studied.

The third section then shows how a change in some structural parameters, namely the intensity of the technical change law, can entail a breakdown in the growth path. 
Bifurcation theory is used to exhibit this possible transition between a "high" and a "low" growth equilibrium.

The fourth section reaches in fact the core of the present theoretical and modelling approach of "structural evolution". It first recalls the stylized story referred to above about the endogenous exhaustion and the crisis of the fordist growth regime. It then emphasizes the specific problem arising from a double time-scale dynamics. The exhaustion of the "growth regime" is modelled as the consequence of its own working in the long run. A specific tool, the slow/fast dynamical systems, appears to be a suitable formal device to capture this double dynamics interaction. Still seldom used in economics, and even less in such a structural change context, slow/fast dynamical systems are briefly presented and then implemented in the former growth framework.

I. EVOLUTION AS MACRO-STRUCTURAL CHANGE : A THEORETICAL PERSPECTIVE TO ADDRESS THE QUESTION OF THE FORDISM CRISIS

It is not a surprise that stylized facts as the early seventies breakdowns in the production and productivity trends caught first the attention of heterodox approaches. Neoclassical economics is still reluctant to address the questions of crisis and structural change. Actually, one of the major rifts within economics surely refers to the place dedicated to history and structural change in growth and economic dynamics theory. It makes a clear-cut divide between "orthodox" approaches on one side and "evolutionary" ones on the other side. But this label of "evolutionary" is very general and rather vague. Evolution is a concept as rich as dangerous : it can apply to whatever you want provided there is "something changing".

In economics the qualification of evolutionary now mainly refers to what could be called a darwino-schumpeterian standpoint. Impulsed by the work of NELSON and WINTER $(1974,1982)$, a line of research considers evolution as the process resulting from the interaction between numerous and heterogeneous agents, competing inside a fluctuating environment which will select the fittest. Their innovation capacity plays the 
role of mutation, and the whole selection process can be seen as the diffusion of the best ${ }^{2}$ innovator species. In such a framework evolution and changes directly come from the agents level and from their interactions, which are the real engine of the dynamics.

Even if the former approach is quite relevant in its specific field, it is possible to suggest that "evolution" can be understood in a very different way. As "current" evolutionism in economics, referred to above, is mainly an individualistic approach, starting at the agents level, we would like to consider here a genuine macroeconomic conception of evolution, following a marxian, rather than a schumpeterian, inspiration. Such an approach seems to fit better the meaning of "structural change" as far as "structure" is regarded as a macroscopic concept. Actually the "structure" can be seen as the set of original mechanisms and functional relationships between aggregate variables, characteristic of a given period and defining a particular "growth regime" (BOYER, 1988b).

The exact nature of the process of change, and the elements to which it applies, in fact completes the distinction we sketched between schumpeterian and marxian standpoints. A schumpeterian point of view is not in itself doomed to be expressed in individualistic terms. But in a macroeconomic framework as well, clusters of innovations appearing randomly and exogenously remain the engine of evolution (SILVERBERG and LEHNERT, 1992). From the present marxian standpoint, structural change appears as the modification of one or several macro (technical, behavioural, institutionnal...) regularities or mechanisms. Furthermore, to follow MARX's dialectical intuition to its conclusion, structural change is also envisaged as an endogenous (and, at least ex-post, deterministic) process. Major transformations of capitalism are not only historical accidents, but often come directly from its own working. Such an endogenous change can lead a "growth regime" to exhaustion and crisis : the coherence that existed initially between its mechanisms is broken as soon as one or several of them have been altered through structural change. Numerous examples of such endogenous structural change and crisis have been provided by contemporary issues of "historical and institutionnal"

\footnotetext{
${ }^{2}$ The selection of the best species corresponds to the "basic" evolutionnary process. In a more complex framework, particularly when there are positive feed-backs (ARTHUR, 1988), the competition process can lead to the selection of less efficient species.
} 
macroeconomics such as, for instance, the french "Regulation school" (AGLIETTA, 1982 ; BOYER, 1988-a, -c).

We certainly do not intend to prevent other conceptions to refer to "evolution", nor to dispute their relevance on the specific questions they are dealing with. It is simply to be noticed that either selection or innovation processes, which make the usual substance of "evolutionary neo-schumpeterian economics", do not perfectly capture the long historical transformations of macro structures with which a marxian standpoint feels more concerned. The concept of evolution in fact calls for numerous perspectives to be exhausted. Macro-structural change just stands one, but not unimportant, among many others.

As an illustration of this general vision, it is interesting to see it working more "concretely" on the historical episod of the seventies crisis. Obviously, it is not possible here to settle a vast and exhaustive panorama of the interpretations elaborated in this framework by the "Regulation school". We will thus only pick up in a very sketchy way some particular notions that will help to build a stylized, and of course partial, scenario of the seventies crisis, but tractable enough to be formalized in a fully fledged growth model.

Among multiple aspects, which are in fact interrelated, these interpretations often emphasize the role of the exhaustion of what could be called the "productivity regime". Understood as the set of mechanisms and institutionnal devices which together shape the productivity dynamics, this very general notion :

i) underscores the key role of technical progress in the growth process, where it is, especially in the long run, a significant and powerful engine besides the mere accumulation of capital ; and

ii) sums up the various - technical but also organizational or social - determinations of the productivity gains. Actually the productivity regime is altogether concerned with the industrial organization, the adequation of the productive structure to the trend and the composition of demand, the inter-firm cooperation, as well as the labour relationships.

Reflecting a kind of global productive efficiency, the "productivity regime" can find a synthetic macroeconomic expression through technical progress "laws" of the KALDOR- 
VERDOORN type. The KALDOR-VERDDORN 's law originally suggests that increasing returns appear due to the deepening of the division of labour and of specialization coming from the extension of the markets (see KALDOR, 1966; BOYER and PETIT, 1991). In fact, as a very macro regularity, linking the productivity growth rate to the production growth rate, it captures, behind the general mechanism of increased specialization, numerous effects and behaviours which overcome largely a purely technological determination, and thus fits the notion of productivity regime.

The possibility of a quantitative macroeconomic appraisal of the productivity regime, its concern with global productive efficiency, the variety of institutional determinations it sums-up, confirm the productivity regime as a genuine macroscopic and structural entity, itself playing the role of a crucial component in the larger structure of the whole "growth regime".

The central impulse role of the productivity regime in the growth process makes it logical to look for at least partial explanations of the crisis in its exhaustion. ${ }^{3}$ Actually this intuition led the "Regulation approach" to derive a bundle of scenarii of the weakening of the fordist regime prevailing during the fifties and sixties (BOYER, 1988-c). One among them, whatever partial, is particularly representative of the evolutionary standpoint refererred to above, and lends itself to be embodied in a tractable growth model depicting an endogenous structural change process leading to the seventies crisis.

Very briefly (see BOYER, 1988-c, or LORENZI, PASTRE, TOLEDANO, 1980 for more detailed expositions) the so-called fordist regime taking place after WW II is initially characterized by a productivity logic relying on the extraction of dynamical returns to scale due to the mass production of long and homogenous series. However the success of the fordist regime progressively erodes its own basis. Actually, the strong and regular increase in the households income and in the standards of living entails a rising preference for diversity, moreover strengthened by the saturation of the fordist consumption norm which shifts households consumption towards a replacement demand. Due to this modification of

\footnotetext{
3 A more faithful interpretation of the "regulation approach" would actually emphasize not only the role of the productivity regime in itself, but also its coherence with the other great components of the growth regime, especially the "'wage-labour nexus" (see BOYER, 1988-a).
} 
tastes in favour of differenciated goods, the final demand ceases to be regular and easily predictible, and becomes higly volatile in trend as well as in composition. The structure of the productive system, previously dedicated to homogenous and standardized goods, does not longer fit the quantitative as well as "qualitative" instability of the demand, making further productivity gains harder to extract.

All these adverse evolutions of the productivity regime appears through the downward shift of the KALDOR-VERDOORN's technical progress law. Indeed, empirical studies (BOYER and PETIT, 1981 ; AMABLE, 1989) confirm the fall in the elasticity of the productivity gains with respect to the growth rate, around the early seventies.

The former scenario is thus interesting for several reasons : i) the exhaustion of the productivity regime consists in a genuine structural change ; ii) moreover, according to the present evolutionary standpoint, this structural change is endogenously induced, and derives from the sole working of the fordist growth regime; iii) at last, it can easily be quantitatively appraised through KALDOR-VERDDORN's law. It therefore makes up an ideal candidate to a macro modelling of the starting of the seventies crisis.

As a matter of fact, such a task was initiated by BOYER (1988-b) with his "growth regimes" formalizations. This was indeed a first and important step as far as it involved and clarified almost all of the theoretical elements relative to the role of the exhaustion of the productivity regime, and to the "structural" character of this evolution. However its formulation in linear terms lacks two important features of the "structural change and crisis" story. First, it does not give to the crisis a suitable form since the instability configuration to which it is associated implies, in a linear model, that the economy either collapses or explodes. But above all it does not account for the endogenous process through which the productivity regime reaches its limits. Giving to the crisis the form of a finer dynamical irregularity, and modelling it explicitely as the consequence of an endogenous structural change process are the respective goals of the following sections. In both steps, nonlinear dynamics will be of a crucial help. 


\section{A GOODWINIAN GROWTH MODEL WITH ENDOGENOUS}

\section{TECHNICAL CHANGE AND PROFIT-SHARING}

It is worth explaining briefly why it is convenient for such a theoretical approach of structural change and crisis to be modelled into a goodwinian framework. Actually, GOODWIN's theoretical project could be summed up as an attempt to formalize MARX and SCHUMPETER's intuitions regarding the evolutionary and unstable character of capitalism. Formalizing the integration between growth and cycle was the first step of GOODWIN's project and gave rise to famous models of endogenous fluctuations (GOODWIN, 1951, and especially GOODWIN, 1967). Unfortunately, its second step aiming structural change was not that successful. Despite the intentions exposed in its last works (GOODWIN and PUNZO, 1988 ; GOODWIN, 1990), his models still continue to depict fluctuating growth rather than genuine structural change, at least in the sense mentionned above. This lack makes it necessary to develop and complete GOODWIN's research program in the direction of macro structural change. The present work could be seen as a contribution in this line. But anyway, because he explicitely intended to reach formalizations of evolution following MARX and SCHUMPETER's visions, and at the same time was a pionner in introducing nonlinear dynamics in economics, choosing a goodwinian framework for a structural change model is a way to acknowledge our debt towards GOODWIN as the inspirer of our own project. ${ }^{4}$

Starting from GOODWIN's famous growth cycle model (1967), it is possible to show that minor but realistic extensions of its hypothesis are sufficient to give way to much richer and robust dynamic patterns and to picture the first elements of a "macro-evolution" approach.

Let us first recall briefly the main features of GOODWIN's original framework. In an economy characterized by constant capital/output ratio, $\sigma=\mathrm{k} / \mathrm{q}$, and productivity trend, $v$ $=\frac{\dot{p}}{\mathrm{p}}$, and where all the wages are consumed and the profits saved and re-invested, the rate of growth is equal to the rate of accumulation and can be written :

\footnotetext{
4 If Goodwin's framework suits particularly the modelling of macro evolution, needless to say this one could take place in quite different frameworks.
} 


$$
\hat{\mathrm{q}}=\frac{(1-\mathbf{u})}{\sigma} \quad \text {, with } \mathrm{u} \text { the wage share in the national income. }
$$

The rate of growth of the rate of employment, $\mathrm{v}$, is thus :

$$
\hat{v}=\hat{q}-\hat{p}=\frac{(1-u)}{\sigma}-v
$$

Besides, it is assumed that the wages rate of growth is determined according a Phillips 's curve :

$$
\hat{\mathbf{w}}=\eta(\mathrm{v})
$$

with : i) $\eta^{\prime}(v)>0$ for all $v \in[0,1]$

ii) $\exists v_{n}>0$ such that $\eta\left(v_{n}\right)=0$

Thus the share of wages varies as :

$$
\hat{u}=\hat{w}-\hat{p}=\eta(v)-v
$$

These assumptions are now modified so as to introduce a complete determination of technical change. Endogenizing productivity's growth is a classical way of extending GOODWIN's model. But none of the extensions previously proposed in this line (SHAHDESAI (1981), VAN DER PLOEG $(1984,1987)$, GLOMBOWSKI and KRÜGER (1987), DE NICOLO (1988) for instance) considered the hypothesis of a KALDORVERDOORN's law. ${ }^{5}$ Actually KALDOR-VERDOORN's law captures a technical change mechanism quite different from the well-known kaldorian technical change function (KALDOR, 1961) often used in the goodwinian literature (see the contributions of VAN DER PLOEG). The latter relies on on mechanization and on the diffusion of knowledge embodied in equipments, and is therefore driven by capital stock per capita. Belonging to a SMITH (1776)-YOUNG (1928) tradition, KALDOR-VERDOORN's law stems from a dynamical scale economies mechanism and is driven by the extension of the outlets.

\footnotetext{
5 However DE NICOLO (1988) mentions BALDUCCI and CANDELA's work (1982) where productivity gains are related to the capital stock growth, which is close, especially when the capitaloutput ratio is constant, to a KALDOR-VERDOORN's law.
} 
Incidentally, it is somehow in the mood of "new growth theories", even if the increasing returns mechanism it involves pictures a specific heterodox way of dealing with the link between endogenous technical change and growth, apart from the mainstream approach à la ROMER (1986-1990)-LUCAS (1988).

Originally considered as a linear relationship between the growth rates of the productivity and of the production, the KALDOR-VERDOORN's law will be here envisaged under a nonlinear and logistic form :

$$
\hat{\mathrm{p}}=\frac{\dot{\mathrm{p}}}{\mathrm{p}}=\phi(\mathrm{g} ; \beta)
$$

where $\mathrm{g}=\hat{\mathrm{q}}$ is the growth rate of the production. The KALDOR-VERDOORN's law will be parametrized by a technical change intensity parameter $\beta>0$, which shifts monotonically the productivity curve, so that :

$$
\forall \mathrm{g}, \quad \frac{\partial \phi(\mathrm{g})}{\partial \beta}>0
$$

The notation will omit $\beta$ when unnecessary : $\phi^{\prime}$ will then implicitly refer to the derivative of $\phi$ with respect to the state variable $g$. At last, $\phi$ fulfills the following assumptions :

i) $\phi^{\prime}(\mathrm{g}) \geq 0$ for all $\mathrm{g} \geq 0$;

ii) $\phi(0) \neq 0$;

iii) $\lim _{\mathrm{g} \rightarrow \infty} \phi(\mathrm{g})$ exists ;

iv) $\exists \tilde{\mathrm{g}}>0 / \phi^{\prime \prime}(\tilde{\mathrm{g}})=0$; and $\phi^{\prime \prime}(\mathrm{g})>0$ when $\mathrm{g}<\tilde{\mathrm{g}} ; \phi^{\prime \prime}(\mathrm{g})<0$ when $\mathrm{g}>\tilde{\mathrm{g}}$ (see figure 1).

It first should be said that logistic forms are more and more acknowledged as valuable economic hypothesis. To mention pionneering works on business cycles, recall for instance KALDOR (1940) sigmoïd investment and saving functions. Technological diffusion too does require logistic patterns (MANSFIELD, 1961). But modern and mainstream theory as well makes use of such formulations, particularly in the "endogenous growth theory". They can depict the strong nonconvexities in technology, giving way to 
the idea of thresholds externalities (AZARIADIS and DRAZEN, 1990 ; FUGATAMI and MINO, 1993), or to the specific form of learning-by-watching (KING, ROBSON, 1990). In fact, as was said above, the comparison between the present framework and "endogenous growth theory" is not irrelevant, at least for two reasons : i) the KALDORVERDOORN's law captures a mechanism of endogenous technical change and makes the growth endogenous instead of being driven by an exogenous productivity trend as in GOODWIN's original model ; ii) both the endogenous growth theory and the present approach are interested in the particular forms increasing returns may exhibit, and take into account the possibility of strong nonconvexities. Even if not micro founded these hypothesis are at the same time economically plausible and capable to give way to rich theoretical results.

Moreover, in the present case, both economic intuitions and empirical evidences help to justify a logistic KALDOR-VERDOORN's law. It is clear that the limited plasticity of the productive system prevents it to exhibit a "convex" reaction to high growth rates stimuli : the extension of the outlets has for its higher values a "decreasing marginal efficiency" in terms of productivity improvement. However, empirical studies (AMABLE, 1989) have shown that the elasticity of the KALDOR-VERDOORN's law (tested under its linear form) was greater for "medium" values of the growth rates of the production than for the lower ones. All this could actually be synthetized through a logistic "sigmoïd" form : its first part sums-up the "convexity" effect observed for low and medium values of the growth rate ; while its second part depicts the "decreasing efficiency" of the specialization deepening that can reasonably be expected for its very high values

We also enrich the determination of wages by adding to the "usual" Phillips term a "profit sharing" term. Even if not micro founded, the rationale behind this term is quite straightforward and can easily be related to WEITZMAN's approach (WEITZMAN, 1985). Apart a "market component" driven by the tensions on labour market, the growth rate of the wages includes another non-market, bargained component indexed on the profit rate, $\mathrm{r}$ :

$$
\hat{w}=\frac{\dot{w}}{w}=\hat{w}_{m}+\hat{w}_{b}
$$




$$
\hat{\mathrm{w}}_{\mathrm{b}}=\delta(\mathrm{g})
$$

since, when the capital-output ratio is constant, the profit rate $r$ is equal to the rate of growth of the production g. We have for $\delta: \delta^{\prime}(\mathrm{g})>0$. At last, summing up the Phillips and the profit sharing effects, we can note :

$$
\hat{\mathrm{w}}=\psi(\mathrm{v}, \mathrm{g})
$$

where the partial derivatives of $\psi$ have the properties of $\eta^{\prime}$ or $\delta^{\prime}$.

Going back to GOODWIN's model, but choosing as a state variable $\mathrm{g}$, the growth rate, instead of $u$, the wage share, to write it under a more compact form, we obtain :

$$
\begin{aligned}
& \frac{\dot{\mathrm{v}}}{\mathrm{v}}=\mathrm{g}-\phi(\mathrm{g}) \\
& \frac{\dot{\mathrm{g}}}{\mathrm{g}}=(1-1 / \sigma \mathrm{g})[\psi(\mathrm{v}, \mathrm{g})-\phi(\mathrm{g})]
\end{aligned}
$$

To make this formulation closer to GOODWIN's original framework, it is possible to read $\mathrm{g}$ as the profit rate in equation (2), so that is kept the "distribution" character of this equation, while, as in GOODWIN (1967), equation (1) with g read as the growth rate, makes the accumulation-employment "block" of the model.

It is worth to enter the technical detail of the resolution to see clearly how the dynamical behaviours of the model rely on the possibility of multiple equilibria and on their stability properties.

We start by studying the existence and the number of equilibria.

* The stationary locus of the employment rate comes from the equality between the production and the productivity growth rates :

$$
\dot{\mathrm{v}}=0 \Rightarrow \mathrm{g}=\phi(\mathrm{g})
$$

Given the logistic form assumed for the productivity function, it is possible to get a graphical "resolution" for the former equation. Figure 1 reveals that there may exist three equilibrium growth rates, $\mathrm{g}^{*} 1,2,3$ (see figure 1 ). 
When $g \neq g *_{i}$ the rate of employment evolves following: $\dot{v}<0$ when $0<g<g *_{1}$ and $\mathrm{g}_{2}<\mathrm{g}<\mathrm{g} *_{3} ;$ and $\dot{\mathrm{v}}>0$ when $\mathrm{g}^{*} 1<\mathrm{g}<\mathrm{g} *_{2}$ and $\mathrm{g}^{*}<\mathrm{g}$.

* The stationary locus of the growth (or profit) rate comes from $\dot{g}=0$. Apart the lines $\mathrm{g}=0$ and $\mathrm{g}=1 / \sigma$, the isocline $[\dot{\mathrm{g}}=0]$ is therefore the locus of the points $\mathrm{v}^{*}(\mathrm{~g})$ implicitly defined by :

$$
\psi(\mathrm{v}, \mathrm{g})=\phi(\mathrm{g})
$$

Acoording to certain parametric conditions (see annex 1 ), the locus $[\dot{g}=0]$ may take five different shapes : monotonically increasing, monotonically decreasing, U-shaped with a minimum, inverse $U$-shaped with a maximum, or with two extrema : a minimum $\overline{\mathrm{g}}_{1}$, and a maximum $\overline{\mathrm{g}}_{2}$ such that $\overline{\mathrm{g}}_{1}<\overline{\mathrm{g}}_{2}$. With $\rho>0$ (Phillips's curve cofficient), and $\forall \mathrm{g}, 1-$ $1 / \sigma g<0,6$ all these configurations exhibit the same variations for the growth rate outside equilibrium : when $v<v^{*}, \dot{g}>0$; when $v>v^{*}, \dot{g}<0$. Phase portraits are then easily obtained (see figure 2 for the richer configuration).

* The phase portraits exhibit three equilibria, the middle-one, $\mathrm{E}_{2}$, being a saddlepoint (see annex 2 for a complete demonstration), therefore unstable, and $\mathrm{E}_{1}$ and $\mathrm{E}_{3}$ being foci (or nodes) (see annex 2) either stable or unstable. We have then the following proposition :

Proposition $1:$ The stationary states $E_{1}$ and $E_{3}$ are locally stable provided the profitsharing term dominates the endogenous technical change term.

The local stability can be studied by looking at the jacobian matrix in the neighbourhood of $E_{1}$ and $E_{3}$. In this particular case where the dynamics is planar and

\footnotetext{
${ }^{6}$ Actually $g_{\max }$ corresponds to $\mathrm{u}=0$ and is such that $g_{\max }=1 / \sigma$.
} 
where $E_{1}$ and $E_{3}$ are foci, the sign of the trace of the jacobian matrix is sufficient to conclude (JORDAN and SMITH, 1987). Noting the particular form of the system :

$$
\begin{aligned}
& \dot{\mathrm{v}}=\mathrm{F}(\mathrm{v}, \mathrm{g})=\mathrm{vf}(\mathrm{g}) \\
& \dot{\mathrm{g}}=\mathrm{H}(\mathrm{v}, \mathrm{g})=\mathrm{gh}(\mathrm{v}, \mathrm{g})
\end{aligned}
$$

and recalling that $f\left(g^{*}\right)=h\left(v^{*}, g^{*}\right)=0$, we get :

$$
\begin{aligned}
& \operatorname{Tr} J\left(v^{*}, g^{*}\right)=\frac{\partial F}{\partial v}\left(v^{*}, g^{*}\right)+\frac{\partial H}{\partial g}\left(v^{*}, g^{*}\right) \\
& \frac{\partial F}{\partial v}\left(v^{*}, g^{*}\right)=0 \\
& \frac{\partial H}{\partial g}\left(v^{*}, g^{*}\right)=g^{*}\left(1-1 / \sigma g^{*}\right)\left[\psi^{\prime} g\left(v^{*}, g^{*}\right)-\phi^{\prime}\left(g^{*}\right)\right]
\end{aligned}
$$

Recalling that $(1-1 / \sigma g)$ is always negative, the equilibria $E_{1}$ and $E_{3}$ are thus stable if :

$$
\begin{aligned}
& \operatorname{Tr} J\left(v^{*}, g^{*}\right)<0, \text { i. e. } \\
& \phi^{\prime}\left(g^{*}\right)<\psi^{\prime} g\left(v^{*}, g^{*}\right)
\end{aligned}
$$

where $\psi_{\mathrm{g}}^{\prime}(\mathrm{v}, \mathrm{g})=\frac{\partial \psi}{\partial \mathrm{g}}(\mathrm{v}, \mathrm{g})=\delta^{\prime}(\mathrm{g})$ captures the derivative of the profit sharing effect.

$$
Q E D
$$

The fact that the dynamics is planar and thus that the stability comes from the sign of $\operatorname{Tr} J=\frac{\partial F}{\partial v}+\frac{\partial H}{\partial g}$ allows this stability property to be interpreted. ${ }^{7}$ The stability can be seen as the resultant of two "partial" stabilities expressed by the two terms $\frac{\partial F}{\partial v}$ and $\frac{\partial H}{\partial g}$ of the trace of the jacobian matrix. Actually, $\frac{\partial F}{\partial v}$ (resp. $\frac{\partial H}{\partial g}$ ) negative means that an increase in the level of $v$ (resp. g) will, all things being equal, decrease its own rate of growth so that its "partial" dynamics is convergent. The local stability of the equilibrium is ensured as soon as both "partial" dynamics are convergent or, at least, as the stabilizing effects of one prevail over the destabilizing effects of the other.

In the present case, it should be noticed that because the employment rate does not 
affect its own growth rate $\left(\frac{\partial F}{\partial v}=0\right)$ the stability is fully determined by the "distribution block" (equation 2) of the model, that is to say according to the sign of $\frac{\partial H}{\partial g}\left(v^{*}, g^{*}\right)=g^{*}(1$ $\left.-1 / \sigma g^{*}\right)\left[\psi^{\prime} g\left(v^{*}, g^{*}\right)-\phi^{\prime}\left(g^{*}\right)\right]$. More precisely, it appears as the resultant of the "partial" stability effects of the productivity law and of the profit-sharing wage term. The former has destabilizing effects : an initial increase in (the growth rate) g moves up the productivity gains and thus, all things being equal, decreases the rate of growth of the wage share and increases the growth rate of (the profit rate) g itself. The technical change "channel" therefore leads $g$ in an unstable "partial dynamics". Conversely, the same initial increase in (the profit rate) $g$ will move up the wages through their bargained component, thus increasing the growth rate of the wage share and decreasing the growth rate of $g$, the partial dynamics of which is therefore convergent. At last, the stability is ensured when the stabilizing effects of the profit-sharing prevail over the destabilizing effects of endogenous technical change with increasing returns, thus when:

$$
\phi^{\prime}\left(g^{*}\right)<\psi^{\prime} g\left(v^{*}, g^{*}\right)
$$

Furthermore, this condition can easily be interpreted geometrically : an equilibrium $\left(E_{1}\right.$ or $\mathrm{E}_{3}$ ) is stable if it belongs to a decreasing branch of the isocline $[\dot{g}=0]$ (see annex 1 ).

\section{STRUCTURAL CHANGE, BIFURCATIONS AND CRISIS}

It is worth noting that though, despite his claims, he did not really propose any genuine model of structural change, GOODWIN had an inkling of the formal device that could allow its formalization :

"The economic problem is the daunting one of finding the responses of an everchanging structure to repeated shocks. In this respect it appears to bear some relation to the highly original new theory of catastrophe. I propose to view the evolution of the economy as a series of changes in parameters" (GOODWIN and PUNZO, 1988, p. 144).

Surprisingly, GOODWIN never applied himself the prescriptions of such an illuminating diagnosis and persisted to use the tools of endogenous fluctuations, surely original and powerful, but less relevant in the case of structural change.

Actually it is convenient both economically and formally to express the "structure" of 
an economy through the set of parameters of a dynamical model. In such a model written as $\dot{x}=f(x), x \in \mathbb{R}^{n}$, the functional form, $f$, sums up all the mechanisms and relationships of the economy. But because it would be difficult, if not impossible, to make a comparative static in the space of functional forms (the dimension of which is infinite) to represent structural change, ${ }^{8}$ it is more convenient to consider the model under the form $\dot{x}=f(x, \lambda)$, $\mathbf{x} \in \mathbf{R}^{\mathrm{n}}, \lambda \in \mathbf{R}^{\mathrm{p}}$ and see the structure as the set of parameters $\lambda=\left(\lambda_{1}, \ldots, \lambda_{\mathrm{p}}\right)$. Structural change can thus be expressed as the passage from a parametric configuration $\left(\lambda_{1}, \ldots, \lambda_{p}\right)$ to another one $\left(\lambda_{1}^{\prime}, \ldots, \lambda_{p}^{\prime}\right)$.

Using this formal expression of the structure, it is possible to study the effects of a structural change, in the present case the exhaustion of the productivity law. Actually, it is now worth to recall that the productivity function is parametrized by the technical change intensity $\beta$ and reads : $\phi(g ; \beta)$. To give an illustration, think for instance to a nonlinear logistic KALDOR-VERDOORN's function which would be written as :

$$
\phi(g ; \beta)=\frac{1}{\alpha+e^{-\beta g}}
$$

A modification in a parameter such as $\beta$, driving the shifts of the productivity regime representative curve, surely deserves the qualification of structural change as was noticed in section $\mathrm{I}$.

To settle the effects of such a structural change, it is practical to assume that all the equilibria $\left(E_{1}\right.$ and $\left.E_{3}\right)$ are locally stable, what can be ensured provided the intensity of the profit-sharing, $\delta^{\prime}=\psi^{\prime} \mathrm{g}$, is high enough (the isocline $[\stackrel{\bullet}{\mathrm{g}}=0]$ is always decreasing). We have then the following proposition :

Proposition 2 : The equilibrium manifold of the system (1)-(2) exhibits two singular points. The crossing of their projections in the control space, $\beta^{*}$ and $\beta^{* *}$, entails a catastrophic bifurcation.

\footnotetext{
8 In particular, structural change could consist in this framework in the emergence of new terms in the functional relations of the system.
} 
Recall that the equilibrium growth rates of the production, $\mathrm{g}^{*}$, are determined by the "accumulation block" of the model, i. e., geometrically, by the intersection $g=\phi(g ; \beta)$. Considering a structural change expressed by a variation in $\beta$, we have :

$$
\forall \mathrm{g}, \quad \frac{\partial \phi(\mathrm{g})}{\partial \beta}>0
$$

for instance, in the previous example :

$$
\frac{\partial \phi(g)}{\partial \beta}=\frac{g e^{-\beta g}}{\left[\alpha+e^{-\beta g}\right]^{2}}>0
$$

so that an increase in the intensity of technical change shifts the productivity curve upwards (see figure 1).

Differentiating the stationarity condition through which are obtained the equilibrium growth rates, namely $g=\phi(g ; \beta)$, we get :

$$
\frac{\mathrm{dg}}{\mathrm{d} \beta}=\frac{\phi^{\prime} \beta}{1-\phi_{\mathrm{g}}^{\prime}}
$$

The medium equilibrium $E_{2}$ is such that $\phi_{\mathrm{g}}^{\prime}\left(\mathrm{g}^{*} 2 ; \beta\right)>1$, while $\mathrm{E}_{1}$ and $\mathrm{E}_{3}$ are such that $\phi_{\mathrm{g}}^{\prime}\left(\mathrm{g}^{*} 1,3 ; \beta\right)<1$. Following a variation in the technical change intensity, the equilibrium growth rates then move following :

$$
\frac{\mathrm{dg}^{*} 1}{\mathrm{~d} \beta}>0 ; \frac{\mathrm{dg}^{*} 2}{\mathrm{~d} \beta}<0 ; \frac{\mathrm{dg} *_{3}}{\mathrm{~d} \beta}>0
$$

The monotonicity of these shifts ensures that, despite the nonlinearity, these local comparative statics results are qualitatively unchanged when $\beta$ varies "in the large". It is thus clear that when $\beta$ increases up to a critical value $\beta^{* *}$, the productivity curve becomes tangent to the accumulation line (here the $45^{\circ}$ line) so that $E_{1}$ and $E_{2}$ are merged. Any following increase in $\beta$ will then make $E_{1}$ and $E_{2}$ vanish so that remains only $E_{3}$. 
Identically, if the intensity of the technical change falls down lower than a second critical threshold $\beta^{*}, E_{2}$ and $E_{3}$ will disappear leaving $E_{1}$ alone.

The equilibrium manifold (figure 3 ) sums-up these variations of the equilibrium growth rates, $\mathrm{g}^{*} \mathrm{i}, \mathrm{i}=1,2,3$, and exhibits two singular points $\mathrm{S}^{*}$ and $\mathrm{S}^{* *}$. Their projection in the control space (here the half real line of the $\beta$ ) give two bifurcation points, $\beta^{*}$ and $\beta^{* *}$ : "far" from them, a "little" change in the parameter leaves the dynamics in the same equivalence class defined for a topological equivalence relationship (ARNOLD, 1973). Basically, two dynamics are topologically equivalent if their flows are homeomorphic. The crossing of a bifurcation point means the dynamics changes its equivalence class, being locally structurally unstable (HALE and KOÇAK, 1991). In the present case, the dynamical system changes qualitatively (topologically) its phase portrait because of the loss of one of its (stable) equilibria ${ }^{9}$.

But beyond these technicalities, these results are of particular interest for a theoretical perspective looking for formal representations of the crisis. Indeed it is tempting to interpret the "fold catastrophe" bifurcation as the dynamical manifestation of the crisis. An economy initially located on the upper growth path, $\mathrm{g}^{*}$, and submitted to a slowdown of its endogenous technical change law, will first move left along the equilibrium manifold and see its growth rate decrease smoothly. But, if the technical change slowdown is large enough, and that is overcome a critical threshold, $\beta^{*}$, the economy incurs a sudden breakdown, making it brutally switch towards the lower growth path corresponding to the equilibrium $\mathrm{g} * 1$.

It is always difficult to expect to capture an economic reality with the help of such a simple and schematic framework. Nevertheless this one seems to fit two important stylized facts of the crisis of the seventies, namely the brutal breakdowns in the trends of the production and of the productivity. Actually, not only the rate of growth of the production incurs a sudden decrease, but, through the KALDOR-VERDOORN's law, the rate of growth of the productivity undergoes an identical breakdown. With the particular

${ }^{9}$ Such an equilibrium manifold, referred to as a "fold" in the catastrophe theory vocabulary (THOM, 1972), exhibits also "historicity", irreversibility and remanence properties summed up under the concept of hysteresis (AMABLE, HENRY, LORDON, TOPOL, 1992). 
dynamical irregularity obtained through the bifurcation, the model gives to the crisis a more realistic and relevant pattern than the diverging linear instability (as in BOYER, 1988-b for instance). But beyond the mere dynamical pattern of the crisis, the model also delivers a rough but plausible interpretation of its starting : the crisis, appearing as a brutal decrease in the trend of output, occurs as an effect of the exhaustion of the "productivity regime". Actually, theoretical interpretations of the seventies' crisis build upon such a fall in the elasticity of the productivity gains (BOYER, 1988-a, -b, -c) which is besides confirmed by empirical studies (BOYER and PETIT, 1981, 1990 ; AMABLE, 1989).

A nonlinear framework therefore permits to link an important change in the "economic regime", namely a structural modification in a major macro-regularity - here the technical change law - and a change in the "dynamical regime" which consists in a qualitative modification of the growth paths (a bifurcation) and appears through a dynamical irregularity. ${ }^{10,11}$ The former is reflected and manifested through the latter. But in its present state, the model only accounts for the effects of a structural change, the dynamics of which remains in fact exogenous : its direction and intensity are arbitrarily decided according to a thought experiment. For our interpretation of the seventies crisis, and, more generally, the modelling of macro-evolution, to be "complete", we need a reason why the "productivity regime" was to weaken and exhaust, namely a stylized scenario of the genesis of structural change which will make it endogenous.

\section{ENDOGENOUS STRUCTURAL CHANGE AND CRISIS}

If it does provide a rather satisfactory formal representation of structural change and crisis, the previous theoretical framework does not address the problem of their

\footnotetext{
${ }^{10}$ It should be noted that a structural change, otherwise called a change in the "economic regime", and consisting basically in a modification of the parametric configuration of the model does not necessarily imply a critical event such as the one occuring in the present framework. Crisis is here an effect of structural change in a particular non linear framework. Under a linear specification, for instance, structural change would not lead to any crisis, at least under the particular form of a dynamical irregularity.

11 Another kind of dynamical irregularity could be derived from this framework : we have shown elsewhere (LORDON, 1993) that a decrease in the intensity of the marxian conflict could lead in certain conditions to a HOPF bifurcation. The equilibrium ceases to be locally stable and is surrounded by an attracting limit cycle. The transition from a regular growth path to an endogenous growth cycle, i.e. a qualitative change in the form of the dynamics towards a greater "instability" can also be seen as a dynamical manifestation of the crisis.
} 
endogeneity. However, here relies one of the main features of MARX 's historical vision of economic dynamics, and, in this line, of a genuine macroeconomics of structural change. The point to capture is that the own working of the structure alters the structure itself. The unfolding of the growth path and the continued process of accumulation induce a slow drift of the structure. According to a rough dialectical intuition, the success of an economic regime, the deepening of its "logic", may gradually generate perverse outcomes which will become in the long run serious obstacles to its further development, or lead to progressive modifications of the behaviours. "Slow" is here the key-word. Actually what characterizes the structure is its greater inertia and much weaker volatility compared to the "growth-cycle" variables. Nevertheless, the slow and sluggish motion of the structure indirectly comes from this "fast" growth dynamics.

These particular features of structural change makes it impossible to endogenize it "simply" as supplementary ordinary state variables. Starting from an initial model $\dot{\mathbf{x}}=$ $\mathrm{f}(\mathbf{x}, \lambda), \mathbf{x} \in \mathbf{R}^{\mathrm{n}}, \lambda \in \mathbf{R}$ and endogenizing $\lambda$ simply as : $\dot{\lambda}=\mathrm{g}(\mathbf{x})$ would be quite misleading. Making of $\lambda$ a new but ordinary state variable would neglect its specificity, compared to the other state variables, $\mathbf{x}$, namely its relative stickiness. One would get there a model giving the same formal statute to "growth-cycle" and "structural" magnitudes, which would thus be formally undistinguishable. There lies however the main problem with endogenous structural change : its formalization must respect the specific characterization of structural aspects through a particular formal statute devoted to their related magnitudes .

More precisely, this particular formal characterization of the structural magnitudes should revolve around their particular time scale, and be expressed through their time constant . 12 By giving to the state variables and the endogenized parameters very different time constants, following for instance :

$$
\begin{aligned}
& \dot{\mathbf{x}}=\mathrm{f}(\mathbf{x}, \lambda) \\
& \dot{\lambda}=\varepsilon \mathrm{g}(\mathbf{x}) \quad \text { with } \quad 0<\varepsilon \ll 1
\end{aligned}
$$

12 The time constant of a state variable involved in a dynamics $\dot{x}=f(x, \lambda)$ consists of the inverse of the first term of a Taylor expansion of $f$ around the equilibrium, this latter mesuring the adjustment speed of the variable. 
it is clearly, and formally, emphasized that the state variables, of the "growth cycle", and endogenized structural "parameters"13 are involved in respectively "fast" and "slow" dynamics. Such a so-called "slow/fast dynamical system" seems thus an appropriate tool for endogenous structural change models. First, it accounts for the structural drift as an endogenous outcome of the growth dynamics. Then it underlines that this outcome appears only in the long run, and that the respectively "slow" and "fast" structural and growth dynamics refer to very different temporal horizons. Of course endogenizing $\lambda$ leads to a meta-model with respect to which $\lambda$ appears as a supplementary state variable. Nevertheless there remains a formal criterion, namely the relative size of the time constants, to distinguish clearly structural from growth or accumulation variables.

This general method could be applied to the previous model on the basis of the scenario exposed in section I, detailing the process of endogenous exhaustion of the productivity regime.

Recall that at the core of this scenario, the increase in the income and standard of living carried by the growth process entails a raising preference for the diversity in the households tastes. Such a modification is detrimental to the efficiency of a productive system assumed to be initially devoted to long and standardized series. Actually its productivity "logic" was relying on dynamical returns to scale and learning-by-doing effects allowed by long and homogeneous series dedicated to mass consumption. This logic does not hold any longer facing the short series of a volatile and highly differenciated demand for goods, the life cycles of which are shorter and shorter. The contradiction between a productive system oriented towards standardized mass production and the new trend and composition of demand leads to the exhaustion of the productivity regime. The diminishing intensity of the productivity law appears then as an endogenous and long run outcome of the previous "fordist". growth regime. Actually this structural change derives from the increasing standard of living caused by the growth process itself. But it takes time before the change in households preferences is expressed and taken into account by the producers. The delay for households to be sure that the purchasing power is really on

13 They were parameters in the initial system but are no longer as soon as they are endogenous. 
an increasing trend beyond the fluctuations of the business cycle, and above all the progressive diffusion of the previous "fordist" consumption norm make the exhaustion of the productivity regime a slow mutation, taking place into a remote horizon dynamics.

It is therefore practical to represent this slow dynamics as driven by a long moving average term on the income :

i) Due to the shortening in the length of the series, the intensity of endogenous technical change moves in the opposite direction of $\mathrm{N}$, the number of differenciated goods ${ }^{14}$ :

$$
\beta(t)=\Gamma[N(t)] \quad \text { with } \Gamma^{\prime}<0
$$

ii) Following the raising preference for diversity, $\mathrm{N}$ itself varies with a "long" income index $\bar{R}(t)$ following :

$$
N(t)=\Omega[\bar{R}(t)] \quad \text { with } \Omega^{\prime}>0
$$

iii) At last, $\bar{R}(t)$ which drives the preference for diversity appears as a moving average on the logarithm of the income $R(t)$, itself evaluated as :

$$
R(t)=\int_{-\infty}^{t} g(s) d s
$$

with $g(s)$ the growth rate of the economy at time $s . \bar{R}(t)$ is therefore written as :

$$
\bar{R}(t)=\int_{-\infty}^{t} \mu(t-\tau) R(\tau) d \tau=\int_{-\infty}^{t} \mu(t-\tau)\left[\int_{-\infty}^{\tau} g(s) d s\right] d \tau
$$

with $\mu(t-\tau)$ the lags distribution. This one is now assumed to be of the exponential type :

$$
\mu(t-\tau)=\frac{1}{T} \exp \left(-\frac{t-\tau}{T}\right)
$$

and, moreover, to be characterized by a mean time lag $\mathrm{T}$, such as : $\mathrm{T} \gg>0$.

\footnotetext{
14 It should be noted that the goods considered here are consumptions goods. This fact justifies that the technical change intensity may fall with the number of (consumption) goods, unlike the "endogenous growth" framework where the technical change pace is positively related to the number of intermediary goods (ROMER, 1990). The former argument revolves around the dilemma between scale and scope economies, whereas the "endogenous growth theory" consider the deepening of the specialization.
} 
Under these hypothesis, it is possible to show:

Proposition $3: \dot{\beta}<0$

Proposition 4: The dynamics of $\beta$ is of the type $\dot{\beta}=\varepsilon P(g)$ with $0<\varepsilon<1$

Proposition 3 : From the hypothesis made on $\beta(t)$ and $N(t)$, it is easy to get :

$$
\begin{aligned}
& \beta=\Omega \circ \Gamma[\bar{R}(t)] \\
& \dot{\beta}=\frac{d \bar{R}(t)}{d t} \quad \Omega^{\prime}[\bar{R}(t)] \quad \Gamma^{\prime}[\Omega(\bar{R}(t))]
\end{aligned}
$$

Recalling that the growth rate of the economy, from which is obtained the current and average incomes, is equal to $: \mathrm{g}=\frac{1-\mathrm{u}}{\sigma}$ with $\mathrm{u}$ the wage share, and that, because of $0<\mathrm{u}<1$, this growth rate is always positive, it is easy to conclude that the current and average incomes, $R(t)$ and $\bar{R}(t)$, are monotonically increasing, so that :

$$
\frac{\mathrm{d} \overline{\mathrm{R}}(\mathrm{t})}{\mathrm{dt}}>0
$$

With $\Gamma^{\prime}<0$ and $\Omega^{\prime}>0$, we obtain : $\quad \dot{\beta}<0$

Proposition 4 : With an exponential lags distribution, the "long" average income is written as :

$$
<R(t)\rangle=\int_{-\infty}^{t} \frac{1}{T} \exp \left(-\frac{t-\tau}{T}\right) R(\tau) d \tau
$$

Using Leibniz 's formula we get :

$$
\frac{\mathrm{d}<\mathrm{R}(\mathrm{t})\rangle}{\mathrm{dt}}=\frac{1}{\mathrm{~T}}[\mathrm{R}(\mathrm{t})-\overline{\mathrm{R}}(\mathrm{t})]
$$

Thus :

$$
\dot{\beta}=\frac{1}{\mathrm{~T}}[\mathrm{R}(\mathrm{g})-\overline{\mathrm{R}}] \Omega^{\prime}(\overline{\mathrm{R}}) \Gamma^{\prime}[\Omega(\overline{\mathrm{R}})]
$$


with: $\quad \frac{1}{\mathrm{~T}} \ll 1$

The whole model appears eventually under the form :

$$
\begin{aligned}
& \frac{\dot{v}}{\mathrm{v}}=\mathrm{g}-\phi(\mathrm{g} ; \beta) \\
& \frac{\dot{\mathrm{g}}}{\mathrm{g}}=(1-1 / \sigma \mathrm{g})[\psi(\mathrm{v}, \mathrm{g})-\phi(\mathrm{g} ; \beta)] \\
& \dot{\beta}=\frac{1}{\mathrm{~T}}[\mathrm{R}(\mathrm{g})-\overline{\mathrm{R}}] \Omega^{\prime}(\overline{\mathrm{R}}) \Psi^{\prime}[\Omega(\overline{\mathrm{R}})]
\end{aligned}
$$

This dynamical system is indeed of the "slow/fast" type. The time constant of $\beta$, when $0<\frac{1}{\mathrm{~T}} \ll 1$, makes it formally distinct from the "short" variables, $\mathrm{v}$ and $\mathrm{g}$.

Because of the relative magnitudes of the time constants of the respectively fast and slow variables, it is thus possible to consider that the former adjust to equilibrium so quickly that meanwhile the latter remains quasi constant. In other words, the structure can be considered as quasi-invariant with the time horizon of the growth cycle. Symetrically, the fast variables can always be considered in quasi equilibrium when the structural magnitude $\beta$ varies following the slow dynamics. Borrowed from the relaxation oscillation theory (GRASMAN, 1987) and from "synergetics" (HAKEN, 1983), through the "adiabatic approximation" (see also ZHANG, 1991 and CHIARELLA, 1990), these adjustment principles of slow/fast dynamical systems can easily be graphically depicted. The fast dynamics adjusts towards the equilibrium ${ }^{15}$ manifold $g^{*}(\beta)$ according to quasi vertical trajectories (see figure 4). When the structural change slow dynamics takes place, the economy can be considered as moving along this equilibrium manifold according to the "order parameter" $(\beta)$ variations.

Assuming that the economy is initially located in an upper ("high" growth)

15 Rigorously speaking one should not speak of equilibria when pointing, as we do here, the stationary states of the fast dynamics alone i. e. consisting of equations (1) and (2) only. 
equilibrium $g^{*} 3$, one gets the following evolution : through the increase of the income due to an always positive growth, the raising preference for diversity entails in the long run a progressive decrease in the intensity of the productivity law. The economy is therefore endogenously displaced along the manifold $g^{*}(\beta)$ in the sense of decreasing $\beta$. When the structural change makes $\beta$ pass below the critical threshold $\beta^{*}$, the economy incurs endogenously a crisis through a breakdown leading to the lower growth path (see figure 4).

Slow/fast dynamical systems provides there a useful device to formalize the articulation between dynamics pertaining to very different time scales. This possibility to represent explicitely the multiplicity of economic time scales is certainly of great importance regarding the question of "evolution". It allows to provide a formal representation of the concepts of endogenous macro-structural change and crisis which, because of their richness and complexity, were most of the time only given semantic characterizations.

Nevertheless such a tool should be handled cautiously. All the analytical conclusions it permits are not necessarily good to be stated. In particular, studying the asymptotic behaviour of the slow dynamics would be merely nonsensical. Actually the long run of a slow dynamics would last one if not several centuries. ${ }^{16}$ Apart from a belief in the "laws of history" it would be difficult to envisage a relevant single and invariant "model" over such a wide period : several major structural changes could have occured in between, leaving the model out of date. Such a model is in fact a "limited range" experiment of thought : a precaution inherited of the historical economics perspective, such as claimed by the "regulation approach", should lead to restrict the set of its conclusions and to consider only the very first structural evolutions it can produce. It would be therefore very risky to extend the slow dynamics far away after the critical breakdown. A structural crisis generally carries major institutionnal changes which upset the previous regularities and leads, through a very historical process, to original ones. If the deterministic framework of the slow/fast dynamical systems is convenient to capture the progressive structural change

\footnotetext{
${ }^{16}$ Actually the time scale of the growth dynamics would be of several years, and the time scale of the "slow structural change" dynamics of several tens of years.
} 
that will lead to the crisis, it is no longer able to deal with the rather indeterminate "institutionnal tatonnement" that follows.

\section{CONCLUSION}

The latter caveat underlines once again the specific meaning we intended to give to the concept of evolution, which, by the way, certainly does not prevent other conceptions to use the same word. Here, "evolution" only emphasizes one among many other "evolutionary features" of the capitalist economies, namely endogenous change in macro regularities. While especially dedicated to capture the slow drift of a growth regime already constituted, it does not address for instance the question of emergent structures characteristic of the "institutional tatonnement" following a structural crisis.

Whatever specific and clearly delimited, this particular conception of evolution is certainly not unimportant to whom believes in the historical variability of "economic laws" and "regimes". It especially underlines the double interaction between growth dynamics and the structural framework where it takes place : i) an economy has the growth path of its structure ; and ii) the unfolding of the growth path in the long run has feedback effects on the structure itself. Actually these ideas could be at the core of a historical macroeconomics which, while concerned by "historical variability" does not give up the perspective of a "scientific" appraisal and of a specific modelling. It might thus be important to develop convenient formal devices in order to capture the two preceeding dynamical principles.

The present paper is an attempt in this line and has focused on two specific formal tools. Firstly, bifurcation theory helps to express the consequences of a special state of the structure on the shape of the growth path. Depending on its "economic regime", appraised through its parametric configuration, an economy is driven by a particular "dynamical regime". In the present case, an intense technical change corresponds to a high growth path, while a weak productivity regime leads into stagnation. In the same line, the use of HOPF's bifucation would have contrasted a regular growth path and an unstable dynamical regime with endogenous growth fluctuations (see LORDON, 1993 for further 
developments in this direction).

But the main contribution of the paper is devoted to the explicit modelling of a multiple time-scales process which corresponds to endogenous structural change. Distinguishing and in the same time coupling these different time-scales dynamics makes the main difficulty of this specific kind of evolutionary modelling. Slow/fast dyamical systems have been proposed here as a solution of this theoretical and formal problem. They certainly contribute to capture the essential features of endogenous structural change and crisis. Heterodox approaches taking seriously these ideas could find numerous scenarii to be formalized with the help of these tools. 


\section{REFERENCES}

AGLIETTA M. (1982) Regulation and crisis of Capitalism, Monthly Review Press, New York.

AMABLE B. (1989), "Economies d'échelle dynamiques, effet d'apprentissage et progrès technique endogène : une comparaison internationale ", Revue de l'IRES, 1.

AMABLE B., HENRY J., LORDON F., TOPOL R. (1992), "Strong Hysteresis : an Application to Foreign Trade", Document de Travail CEPREMAP n 9216.

ARNOLD V. (1973), Ordinary Differential Equations, MIT Press, Cambridge, Mass.

ARTHUR B. (1988), "Competing Technologies : an Overview", in DOSI et alii (eds), Technical Change and Economic Theory, Pinter, London.

AZARIADIS C., DRAZEN A. (1990) "Threshold Externalities in Economic Development", Quarterly Journal of Economics, CV.

BALDUCCI R., CANDELA G. (1982), Contrattazzione salariale e ciclo economico, Roma, La Nuova Italia Scientifica.

BOULDING K. (1981), Evolutionary Economics, Sage Publications, London.

BOWLES S., GORDON D., WEISSKOPF T. (1983), Beyond the Waste Land, New York, Anchor Press.

BOYER R. (1988-a), "Technical Change and the theory of 'Regulation' ", in DOSI et alii (eds), Technical Change and Economic Theory, Pinter, London.

BOYER R. (1988-b), "Formalizing Growth Regimes", in DOSI et alii (eds), Technical Change and Economic Theory, Pinter, London.

BOYER R. (ed) (1988-c), The Search for Labour Market Flexibility, Clarendon Press, Oxford.

BOYER R., PETIT P. (1981), "Employment and Productivity in the EEC", Cambridge Journal of Economics, $5,1$.

BOYER R. and PETIT P.(1990), "Technical Change, Cumulative Causation and Growth : Accounting for the Contemporary Productivity Puzzle with some Postkeynesian Theories", in The Challenge of the Economic Policy, Paris, OECD.

BOYER R. and PETIT P.(1991) "Kaldor's Growth Theories : Past, Present and Prospects for the Future", in Semmler W. and Nell E. (eds), Nicholas Kaldor and Mainstreams Economics, Mac Millan, London.

CHIARELLA C. (1990), The Elements of a Nonlinear Theory of Economic Dynamics, Lecture Notes in Economics and Mathematical Systems, Springer Verlag, Berlin.

DE NICOLO (1988) "Learning by doing and Cyclical Growth", in Ricci G. and Velupillai $\mathrm{K}$. (eds), Growth Cycles and Multisectoral Economics in the Goodwinian Tradition, Lecture Notes in Economics and Mathematical Systems, 309, Springer Verlag, Berlin.

FREEMAN C., PEREZ C. (1988), "Structural Crisis of Adjustment : Business Cycles and Investment", in DOSI et alii (eds), Technical Change and Economic Theory, Pinter, 
London.

FUGATAMI K., MINO K. (1993), "Threshold Externalities and Cyclical Growth in a Stylized Model of Capital Accumulation", Economics Letters, 41, p. 99-105.

GLOMBOWKI J., KRÜGER M. (1987), "Generalizations of Goodwin's Growth Cycle Model", in Batten D., Casti J., Johansonn B. (eds), Economic Evolution and Structural Adjustment, Lecture Notes in Economics and Mathematical Systems, Springer Verlag.

GLYN A.; HUGHES A., LIPIETZ A., SINGH A. (1990), "The Rise and Fall of the Golden Age", in Marglin S, Schor J. (eds), The Golden Age of Capitalism, Clarendon Press, Oxford.

GOODWIN R. (1951), "The Nonlinear Accelerator and the Persistence of Business Cycles", Econometrica, 19.

GOODWIN R. (1967) "A growth Cycle", in Feinstein (ed), Socialism, Capitalism and Economic Growth, Cambridge.

GOODWIN (1990) Chaotic Economic Dynamics, Clarendon Press, Oxford

GOODWIN R. and PUNZO L. (1988) The Dynamics of a Capitalist Economy, Polity, London.

GRASMAN J. (1987) Asymptotic Methods for Relaxation Oscillations and Applications, Applied Mathematical Sciences, 63, Springer Verlag.

HAKEN H. (1983), Advanced Synergetics, Springer Verlag, Berlin.

HALE J., KOÇAK H. (1991), Dynamics and Bifurcations, Springer Verlag, Berlin.

JORDAN D. W. and SMITH P. (1987) Nonlinear Ordinary Differential Equations, Oxford Applied Mathematics and Computing Science Series, Oxford.

KALDOR N. (1940) "A Model of the Trade Cycle", Economic Journal, 50.

KALDOR N. (1961), "Capital Accumulation and Economic Growth", in LUTZ F. (ed), The Theory of Capital, Mac Millan, London.

KALDOR N. (1966) Causes of the slow rate of growth in the United Kingdom, Cambridge University Press, Cambridge.

KING M., ROBSON M. (1990), "Endogenous Growth and the Role of History", Colloque "Instabilité et Persistance", Sénat.

LORDON F. (1993), Irrégularités des trajectoires de croissance, évolutions et dynamique non-linéaire. Vers une schématisation de l'endométabolisme, Thèse EHESS, Paris.

LORENZI J. H., PASTRE O., TOLEDANO J. (1980), La Crise du XXe siècle, Economica, Paris.

LUCAS R. (1988) "On the mechanics of economic development", Journal of Monetary Economics, 22.

MANSFIELD E. (1961), "Technical Change and the Rate of Imitation", Econometrica, October.

NELSON R., WINTER S. G. (1974), "Neoclassical vs. Evolutionary Theories of Economic Growth", Economic Journal, 84.

NELSON R., WINTER S. G. (1982), An Evolutionary Theory of Technical 
Change, Cambridge, Harvard University Press.

PERRON P. (1990), "Further Evidence for Breaking Trend Functions in Macroeconomic Variables", Princeton University, Working Paper $n^{\circ} 350$.

MARGLIN S. and BHADURI A. (1986) "Distribution, capacity utilization and growth", mimeo WIDER.

ROMER P. (1990) "Endogenous technological change", Journal of Political Economy,

SHAH A. and DESAI M. (1981) "Growth cycles with induced technical change", Economic Journal, December.

SILVERBERG G. , LEHNERT (1992), "Long Waves and Evolutionary Chaos in a Simple Schumpeterian Model of Embodied Technical Change", MERIT Research Memorandum $n^{\circ}$ 92-023.

THOM R. (1972), Stabilité structurelle et morphogénèse, Benjamin, New York.

VAN DER PLOEG (1984) "Implications of workers' savings for economic growth and the class struggle", in Goodwin R., Krïger M. and Vercelli A. (eds) Nonlinear models of fluctuating growth, Lecture Notes in Economics and Mathematical Systems, Springer Verlag, Berlin.

VAN DER PLOEG (1987), "Growth Cycles, Induced Technical Change, and Perpetual Conflict over the Distribution of Income", Journal of Macroeconomics, vol. $9, \mathrm{n}^{\circ} 1$.

WEITZMAN M. (1985), "The Simple Macroeconomics of Profit Sharing", American Economic Review, december.

YOUNG A. (1928), "Increasing Returns and Economic Progress", Economic Journal, December.

ZHANG W. B. (1991), Synergetic Economics, Springer Verlag, Berlin. 


\section{ANNEX 1 \\ Different configurations of the isocline $[\dot{g}=0$}

The isocline $[\mathrm{g}=0]$ is the locus of the points such that :

$$
\psi(\mathrm{v}, \mathrm{g})=\phi(\mathrm{g})
$$

Differentiating this expression, the slope of $[\dot{\mathrm{g}}=0]$ may be written as :

$$
\left.\frac{d v}{d g}\right|_{[\dot{g}=0]}=\frac{\phi^{\prime}(g)-\psi^{\prime} g(v, g)}{\psi^{i}{ }_{v}(v, g)}
$$

Taking into account that the Phillips term ensures a strictly positive partial derivative $\psi_{v}^{\prime}$, the extrema of the isocline $[\dot{\mathrm{g}}=0]$ correspond to :

$$
\phi^{\prime}(\mathrm{g})=\psi_{\mathrm{g}}^{\prime}(\mathrm{v}, \mathrm{g})
$$

Given the assumptions made on $\phi$, we may say that $\phi$ ' has the following shape :

In the particular case where $\psi$ is linear and increasing in $g\left(\psi_{g}^{\prime}(v, g)=\delta\right)$, we may have five configurations depending on the relative places of the graphs of $\psi^{\prime}$ and $\phi^{\prime}$ : 
1) $\delta<\operatorname{Min}\left\{\phi^{\prime}(0) ; \phi^{\prime}\left(g_{\max }\right)\right\}$

There exist no $\overline{\mathrm{g}}$ such that $\delta=\phi(\overline{\mathrm{g}})$. Moreover, $\left.\forall \mathrm{g} \frac{\mathrm{dv}}{\mathrm{dg}}\right|_{[\dot{\mathrm{g}}=0]}>0$. The isocline $[\dot{\mathrm{g}}$ $=0]$ is thus monotonically inceasing.

2) $\quad \psi^{\prime}(0)<\delta<\psi^{\prime}\left(g_{\max }\right)$

There exist $\overline{\mathrm{g}}$ such that $\delta=\phi^{\prime}(\overline{\mathrm{g}})$. Moreover, $\mathrm{g}<\overline{\mathrm{g}}$ implies $\left.\left.\frac{\mathrm{dv}}{\mathrm{dg}}\right|_{[\mathrm{g}}=0\right]>0$. The isocline $[\dot{\mathrm{g}}=0]$ is thus inverse $\mathrm{U}$-shaped with a maximum in $\overline{\mathrm{g}}$.

3) $\psi^{\prime}\left(g_{\max }\right)<\delta<\psi^{\prime}(0)$

There exist $\overline{\mathrm{g}}$ such that $\delta=\phi^{\prime}(\overline{\mathrm{g}})$. Moreover, $\mathrm{g}<\overline{\mathrm{g}}$ implies $\left.\frac{\mathrm{dv}}{\mathrm{dg}}\right|_{[\mathrm{g}=0]}<0$. The isocline $[\dot{\mathrm{g}}=0]$ is thus $\mathrm{U}$-shaped with a minimum in $\overrightarrow{\mathrm{g}}$.

4) $\operatorname{Max}\left\{\phi^{\prime}(0) ; \phi^{\prime}\left(g_{\max }\right)\right\}<\delta<\phi^{\prime}(\tilde{\mathrm{g}})$

$[\dot{\mathrm{g}}=0]$ has a minimum $\overline{\mathrm{g}}_{1}$ and a maximum $\overline{\mathrm{g}}_{2}$ such that $\overline{\mathrm{g}}_{1}<\overline{\mathrm{g}}_{2}$.

5) $\phi^{\prime}(\tilde{\mathrm{g}})<\delta$

There is no extremum and the isocline $\left[\mathrm{g}^{*}=0\right]$ is monotonically decreasing.

These five configurations can also be obtained for any $\psi(v, g)$ monotonically increasing in $\mathrm{g}$, the second partial derivative of which with respect to $\mathrm{g}$ is of constant sign, and not too strongly concave or convex. 
ANNEX 2

\section{Classification of the equilibria}

A sufficient condition for $E_{2}$ being a saddle-point is that the determinant of the jacobian matrix in $E_{2}$ be negative.

The dynamical system is written :

$$
\begin{aligned}
& \dot{\mathrm{v}}=\mathrm{F}(\mathrm{v}, \mathrm{g})=\mathrm{v} f(\mathrm{~g})=\mathrm{v}[\mathrm{g}-\phi(\mathrm{g})] \\
& \dot{\mathrm{g}}=\mathrm{H}(\mathrm{v}, \mathrm{g})=\mathrm{g} \mathrm{h}(\mathrm{v}, \mathrm{g})=\mathrm{g}(1-1 / \sigma g)[\psi(\mathrm{v}, \mathrm{g})-\phi(\mathrm{g})]
\end{aligned}
$$

and recalling that $f\left(g^{*}\right)=h\left(v^{*}, g^{*}\right)=0$, we get :

$$
\begin{aligned}
& \frac{\partial \mathrm{F}}{\partial \mathrm{v}}\left(\mathrm{v}^{*}, \mathrm{~g}^{*}\right)=0 \\
& \frac{\partial \mathrm{F}}{\partial \mathrm{g}}\left(\mathrm{v}^{*}, \mathrm{~g}^{*}\right)=\mathrm{v}^{*} \mathrm{f}^{\prime}\left(\mathrm{g}^{*}\right) \\
& \frac{\partial \mathrm{H}}{\partial \mathrm{v}}\left(\mathrm{v}^{*}, \mathrm{~g}^{*}\right)=\mathrm{g}^{*} \frac{\partial \mathrm{h}}{\partial \mathrm{v}}\left(\mathrm{v}^{*}, \mathrm{~g}^{*}\right)=\rho \mathrm{g}^{*}\left(1-1 / \sigma \mathrm{g}^{*}\right) \\
& \frac{\partial \mathrm{H}}{\partial \mathrm{g}}\left(\mathrm{v}^{*}, \mathrm{~g}^{*}\right)=\mathrm{g}^{*}\left(1-1 / \sigma \mathrm{g}^{*}\right)\left[\psi^{\prime} \mathrm{g}(\mathrm{v}, \mathrm{g})-\phi^{\prime}\left(\mathrm{g}^{*}\right)\right]
\end{aligned}
$$

We have thus :

$$
\begin{aligned}
\operatorname{Det}\left(\mathrm{u}^{*}, \mathrm{v}^{*}\right) & =\frac{\partial \mathrm{F}}{\partial \mathrm{v}} \frac{\partial \mathrm{H}}{\partial \mathrm{g}}-\frac{\partial \mathrm{F}}{\partial \mathrm{g}} \frac{\partial \mathrm{H}}{\partial \mathrm{v}} \\
& =-\frac{\partial \mathrm{F}}{\partial \mathrm{g}} \frac{\partial \mathrm{H}}{\partial \mathrm{v}} \\
& =-\rho \mathrm{g}^{*}\left(1-1 / \sigma \mathrm{g}^{*}\right) \mathrm{v}^{*} \mathrm{f}^{\prime}\left(\mathrm{g}^{*}\right) \\
& =-\rho \mathrm{g}^{*}\left(1-1 / \sigma \mathrm{g}^{*}\right) \mathrm{v}^{*}\left[1-\phi^{\prime}\left(\mathrm{g}^{*}\right)\right]
\end{aligned}
$$

In $E_{2}$, the intersection between the accumulation line (the $45^{\circ}$ line) and the productivity curve $\phi(g)$ is such that $\phi^{\prime}\left(g^{*} 2\right)>1$ (see figure 1$)$. Recalling that $\left(1-1 / \sigma g^{*}\right)<0$, we have : 
and $E_{2}$ is a saddle-point.

Conversely, in $E_{1}$ and $E_{3}$, the intersection between the accumulation line and the productivity curve is such that $\phi^{\prime}\left(\mathrm{g}^{*} 1,3\right)>1$ (see figure 1). Thus :

$$
\operatorname{Det} \mathrm{J}\left(\mathrm{v}^{*} 1,3, \mathrm{~g}^{*} 1,3\right)>0
$$

$E_{1}$ and $E_{3}$ are therefore nodes or foci. 


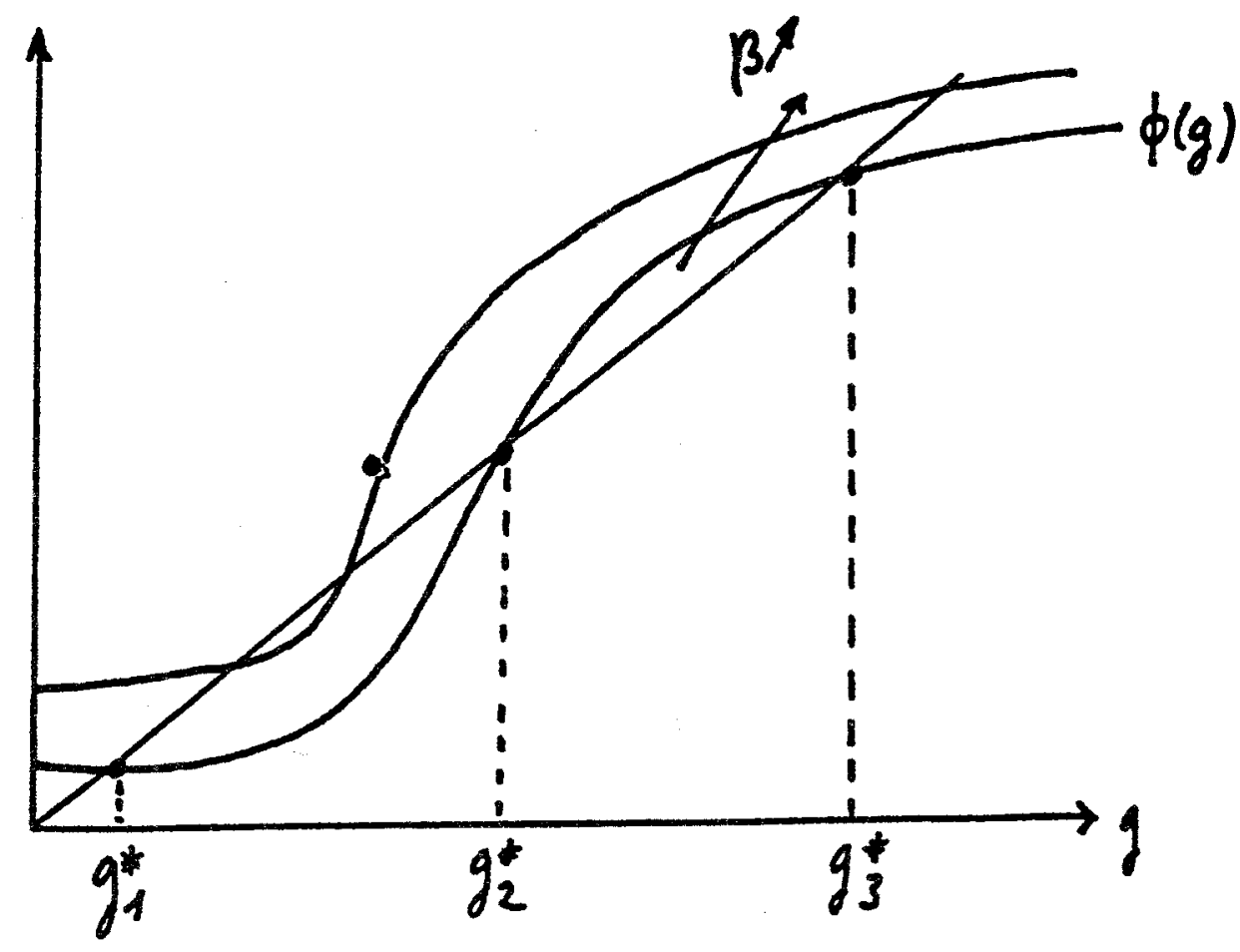

Figure 1

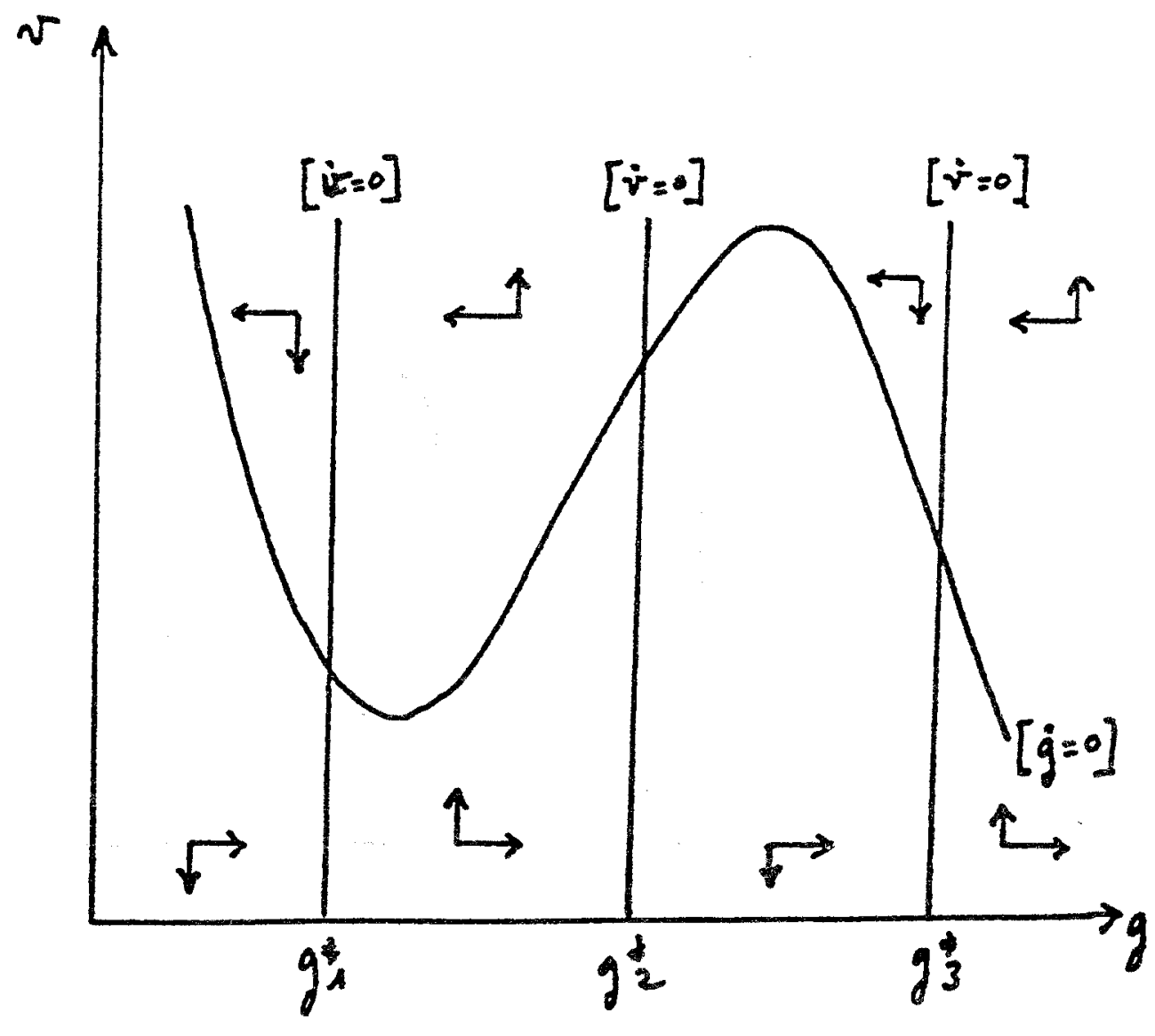

Figure 2 


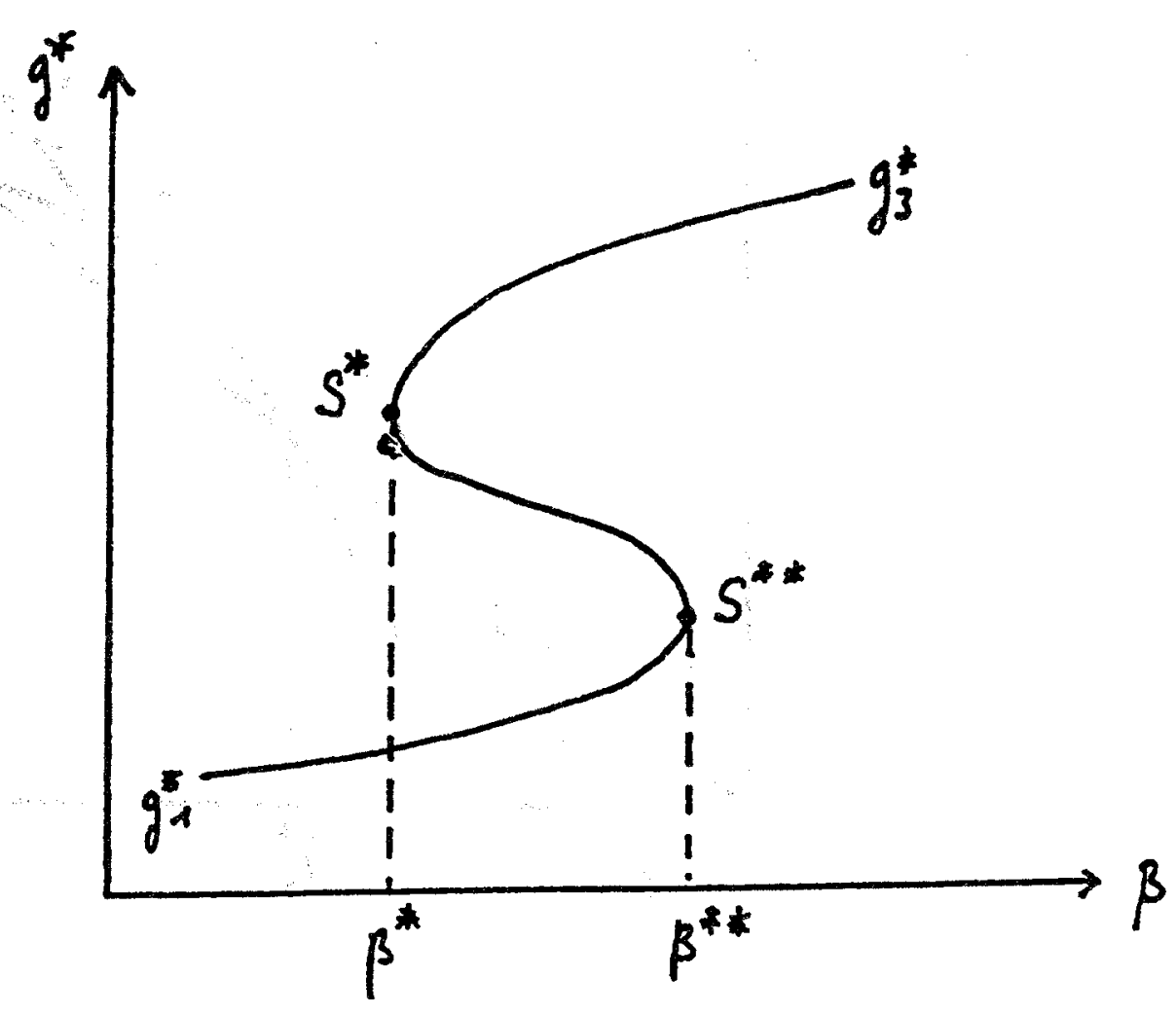

Figure 3

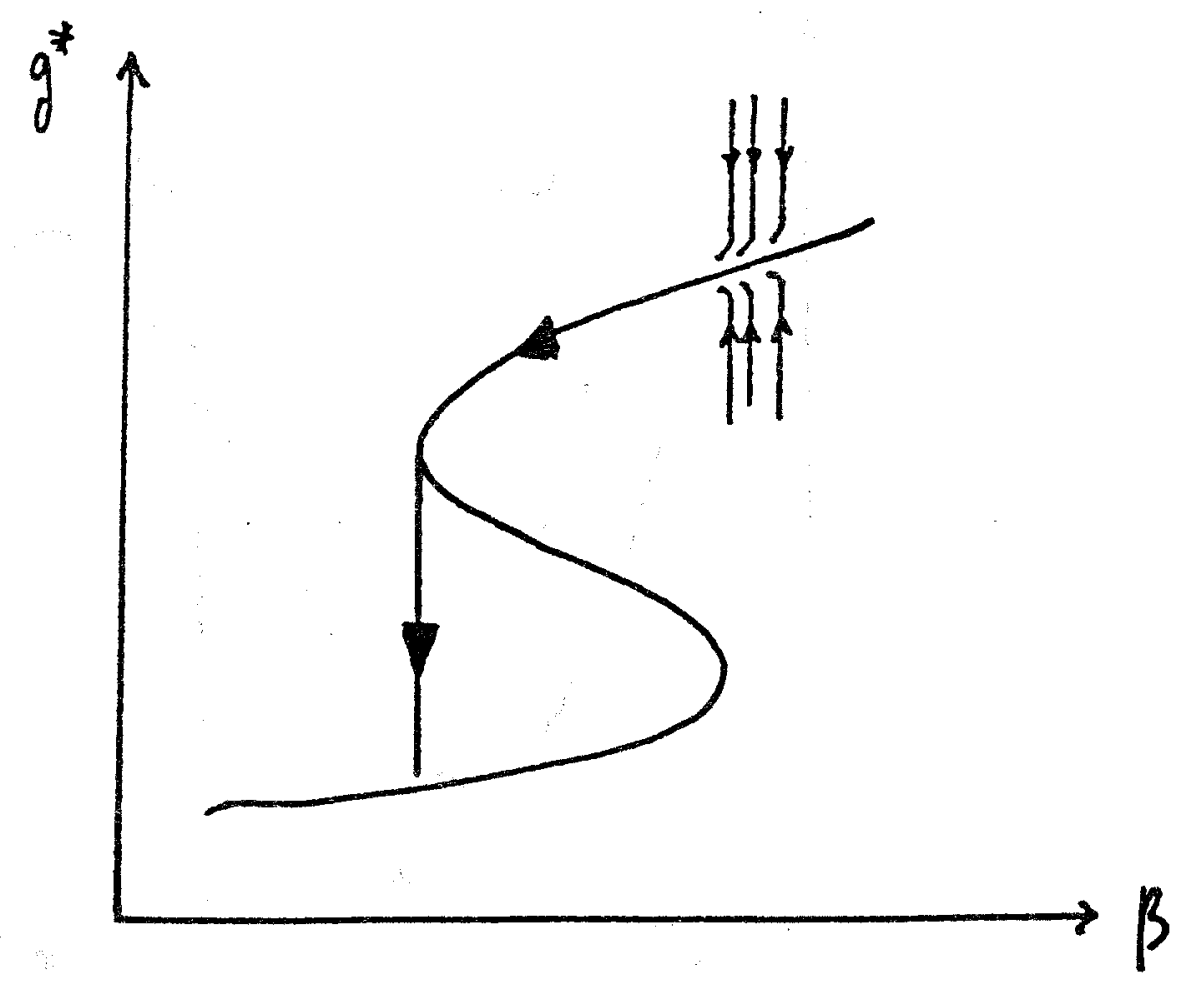

Figure 4 